See Article page 384

\section{Commentary: Taking to heart the challenge of primary cardiac sarcoma}

\author{
Vinod Ravi, MD, and Michael J. Reardon, MD
}

Primary cardiac sarcoma is a rare disease with which few surgeons or even institutions gain substantial experience. We recently reviewed a 42-year experience in the Surveillance, Epidemiology, and End Results (SEER) database covering 10,038,818 records from which 442 cases of primary cardiac sarcoma were extracted for study. ${ }^{1}$ The patients tend to be young, with a mean age of 47.2 years. Survival in this national study was poor, with a mean survival of 7 months and 1-, 3-, and 5-year survivals of $40.7 \%, 15.6 \%$, and $9.8 \%$. Both surgery and chemotherapy were associated with increased survival. Our previous report on primary cardiac sarcoma included 131 cardiac sarcoma evaluations leading to 95 surgical resections during a 25 -year period. ${ }^{2}$ We recently reported our updated series of 122 surgical resections for primary cardiac sarcoma at the 101st Annual Meeting of The American Association for Thoracic Surgery. ${ }^{3}$ These were again young patients, with a mean age of 45.3 years. The majority of these cases had been originally operated on elsewhere and were referred to us after recurrence. The mean survival from their initial diagnosis was 871 days and from surgery at our institution was 467 days. The 1-, 3-, and 5-year survival from surgery at our institution was $57.1 \%, 24.5 \%$, and $15.6 \%$. Almost all deaths were related to distant metastatic disease, and no improvement in survival was seen between the first and second halves of the study, suggesting this is a systemic disease from the start and better systemic therapies, both

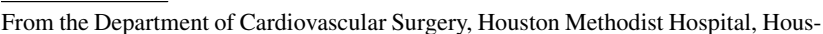
ton, Tex.

Disclosures: The authors reported no conflicts of interest.

The Journal policy requires editors and reviewers to disclose conflicts of interest and to decline handling or reviewing manuscripts for which they may have a conflict of interest. The editors and reviewers of this article have no conflicts of interest.

Received for publication Sept 13, 2021; revisions received Sept 13, 2021; accepted for publication Sept 17, 2021; available ahead of print Oct 4, 2021.

Address for reprints: Michael J. Reardon, MD, Department of Cardiovascular Surgery, Houston Methodist Hospital, 6550 Fannin, Suite 1401, Houston, TX 77030 (E-mail: mreardon@houstonmethodist.org).

JTCVS Open 2021;8:391-2

2666-2736

Copyright (c) 2021 The Author(s). Published by Elsevier Inc. on behalf of The American Association for Thoracic Surgery. This is an open access article under the CC BY-NC-ND license (http://creativecommons.org/licenses/by-nc-nd/4.0/)

https://doi.org/10.1016/j.xjon.2021.09.030
}

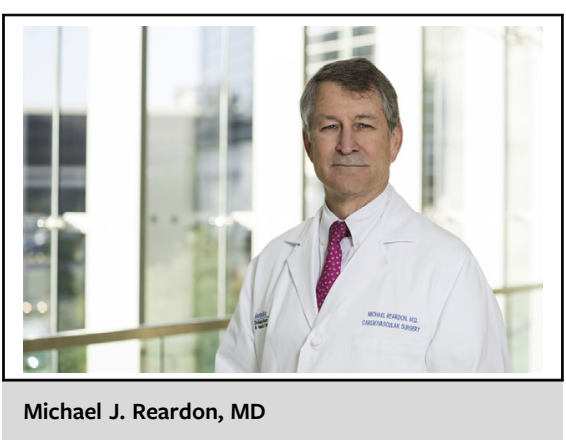

CENTRAL MESSAGE

Cardiac sarcoma is a rare disease with poor prognosis. Surgery extends survival and remains the mainstay of therapy. The evaluation and care are best undertaken in centers of excellence.

biologic and targeted, are necessary. In light of these results, we welcome additional investigators taking on this difficult disease process.

In this issue of the Journal, Hasan and colleagues ${ }^{4}$ from the Cleveland Clinic present their institutional experience with surgical resection of primary cardiac sarcoma. Over a 35-year period, at one of the busiest heart centers in the world, they operated on 32 patients with cardiac sarcoma. The patients were young, with a mean age at 48 years. In the operating room, 6 patients were deemed unresectable and only debulked. This likely represents the very early portion of the study, when imaging was much less precise. The remaining $26(81 \%)$ underwent resection for potential cure. The R0 resection rate was $25 \%$, and the operative mortality was 0 . Median survival was 3 years, but there was substantial loss to follow-up in this patient population, which often came from a great distance from the Clinic, making follow up difficult. These are excellent results and attest to the skill and dedication of the Cleveland Clinic team at all levels.

Experiences such as these add to our cumulative knowledge of this disease process and help us move the field forward. My only issue with the paper is the excellent surgical video that was submitted. The video demonstrates the removal of a large tumor involving the inferior vena cava, right atrium, and left atrium. The surgical approach to this complex situation is methodical, illustrative, and masterful, 
the final outcome is excellent. The problem is that this is not a primary cardiac sarcoma but an extremity myxoid sarcoma that is now metastatic to the heart and present for 4 years before resection. A previous review of the SEER database for sarcomas covering 1988 to 2005 found 210 primary cardiac sarcoma and 24,404 soft-tissue sarcomas. ${ }^{5}$ Median survival for primary cardiac sarcoma was 6 months and for noncardiac soft-tissue sarcoma was 96 months. Many of our treatment strategies are based on the experience with the more common soft-tissue sarcomas at other sites, but it should be recognized that these are very different diseases. In addition to histology, site also has an impact on survival. Survival of angiosarcoma occurring in the head and neck region or extremity is several fold greater than the survival of angiosarcoma arising in the heart. If this case, as it appears, is included in this study, the median survival is likely biased in favor of longer survival and should be interpreted with caution.

This manuscript makes a number of points that any surgeon (or tumor team) interested in treating primary cardiac sarcoma should take to heart. The authors note the improvement in our imaging ability and how this impacts our ability to plan and deliver therapy. Every left atrial sarcoma referred to our group was originally operated on with the misdiagnosis of myxoma and several of our pulmonary artery sarcomas thought originally to be pulmonary emboli. Understanding the imaging characteristics that allow one to differentiate between benign and malignant masses is crucial. ${ }^{6,7} \mathrm{We}$ also strongly agree with the authors' approach of using a multidisciplinary team to evaluate and treat these patients. ${ }^{8}$ The excellent data provided in this report by the Cleveland Clinic team move our knowledge of primary cardiac sarcoma forward but is still a small series as it stands alone. We have currently started an international database, christened INTErnational Registry to Assess Cardiac Tumours (INTERACT), organized by Drs Cusimano and Farkouh of the University of Toronto to help expand our knowledge of this disease. Finally, we believe that primary cardiac sarcoma is a systemic disease at presentation in almost all cases. Better understanding of the tumor biology and immunology of this disease and therapies that leverage these insights is acutely needed. In conjunction with the MD Anderson Cancer Center, we have started a multidisciplinary effort that brings together functional genomics, immunology, and cell-based therapies in the context of cardiac sarcomas. The overall goal of this effort is to generate a better understanding of genetic and molecular mechanisms underlying the pathogenesis of cardiac sarcomas and to use these insights to develop novel systemic targeted therapies. Cell therapies and immune oncology agents that leverage the immune system to mount a more durable response to this systemic disease are also a key focus of this collaboration. Multiinstitutional collaborations with integrated clinical and molecular data accessible to the research community at large and an efficient network of clinical trial sites to translate the insights generated are critically needed in this rare and highly fatal cancer.

We again congratulate the authors on their outstanding results and thank them for adding knowledge that takes us to the heart of this challenging disease.

\section{References}

1. Yin K, Luo R, Wei Y, Wang F, Zhang Y, Karlson KJ, et al. Survival outcomes in patients with primary cardiac sarcoma in the United States. J Thorac Cardiovasc Surg. 2021;162:107-15.e2.

2. Ramlawi B, Leja MJ, Abu Saleh WK, Al Jabbari O, Benjamin R, Ravi V, et al. Surgical treatment of primary cardiac sarcomas: review of a single-institution experience. Ann Thorac Surg. 2016;101:698-702.

3. Chan EY, Ali A, Zubair MM, Nguyen DT, Ibarra-Cortez SH, Graviss EA, et al. Primary cardiac sarcomas: treatment strategies. J Thorac Cardiovasc Surg. Forthcoming 2022.

4. Hasan SM, Witten J, Collier P, Tong MZ, Pettersson GB, Smedira NG, et al. Outcomes after resection of primary cardiac sarcoma. J Thorac Cardiovasc Surg Open. 2021;8:384-90.

5. Hamidi M, Moody JS, Weigel TL, Kozak KR. Primary cardiac sarcoma. Ann Thorac Surg. 2010;90:176-81.

6. Kassi M, Polsani V, Schutt RC, Wong S, Nabi F, Reardon MJ, et al. Differentiating benign from malignant cardiac tumors with cardiac magnetic resonance imaging. J Thorac Cardiovasc Surg. 2019;157:1912-22.e2.

7. Wyler von Ballmoos MC, Chan EY, Reardon MJ. Imaging and surgical treatment of primary pulmonary artery sarcoma. Int J Cardiovasc Imaging. 2019;35: 1429-33.

8. Lestuzzi C, Reardon MJ. Primary cardiac malignancies: the need for a multidisciplinary approach and the role of the cardio-oncologist. J Am Coll Cardiol. 2020; 75:2348-51. 